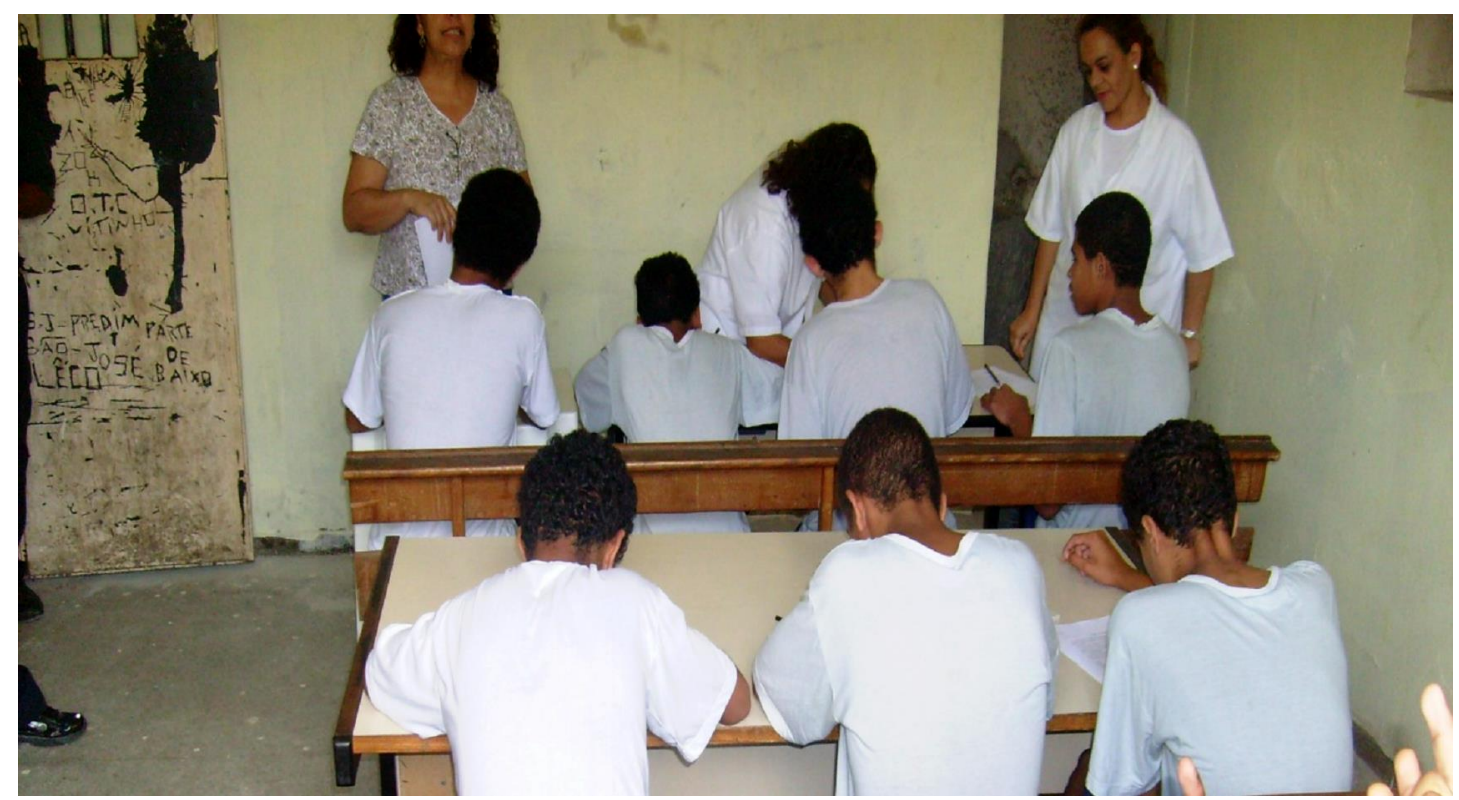

Alunos durante o teste diagnóstico pedagógico

\title{
O adolescente infrator rumo a novas oportunidades
}

\section{Maria da Pompéia Carneiro}

Agradecimentos:

Professora Maria Antonieta Pereira

Professor Erilton

Maria da Pompéia Carneiro é pedagoga e funcionária do CEIP Dom BOSCO.

A internação de um adolescente em uma unidade socioeducativa é - fundo do poço para muitas famílias. Para outras, pode vir a ser a oportunidade de preservar ainda por algum tempo a vida destes, visto que as "guerras" do "mundão", por disputa de pontos de tráfico ou por débitos de droga, já os coloca na posição de condenados à morte. Mas para nós, educadores do CEIP-DB, é uma oportunidade de resgate de valores que norteiam a formação cidadã.

- Centro de Internação Provisória Dom Bosco, localizado no bairro Horto em Belo Horizonte - MG, é uma instituição de acautelamento de adolescentes em conflito com a lei, com idade entre 12 e 18 anos incompletos. O período legal de 
acautelamento é de no máximo 45 dias, sendo que adolescentes que receberam medida socioeducativa de internação ficam na instituição aguardando liberação de vaga em centros próprios para cumprimento da medida, podendo o período de espera se estender por até 120 dias. As peculiaridades do provisório e a rotatividade do público atendido, aliadas à vulnerabilidade social das comunidades às quais eles pertencem, demandam ações direcionadas para a democratização de linguagens e recursos pedagógicos que contribuam para melhorar a auto-estima e ampliar o leque da identidade cultural dos acautelados.

Com foco nos objetivos de ressocialização, a Direção Geral e a Coordenação Pedagógica do CEIP, em parceria com educadores do Programa $A$ tela e o texto da UFMG, implantaram o projeto "Juventude: leituras da inclusão" que foi desdobrado no projeto "Semear letras e cultivar conhecimentos" em 02/02/2009, como alternativa de resgate e difusão cultural, utilizando a tecnologia como recurso didático. A proposta foi orientada pelo resultado de diagnóstico pedagógico, em teste de leitura, escrita e interpretação de texto, aplicado aos internos em um momento pontual, que detectou um déficitde desenvolvimento intelectual dos alunos em relação à sua classificação escolar e a ausência de identidade escolar nos adolescentes que, em sua maioria, se encontravam evadidos da escola regular quando de seu acautelamento.

O projeto educativo do CEIP-DB tem como função principal a interação entre as diversas áreas e profissionais da comunidade educativa, formando, assim, uma equipe multidisciplinar que contribua para a formação dos adolescentes e a conscientização de que há caminhos diferentes daqueles que os conduziram para a condição de sujeitos com liberdade restrita. O grande desafio inicial foi selecionar, entre vários profissionais capacitados e comprometidos, alguns agentes socieducadores para atuar como referência no espaço escolar. O desafio diário é desconstruir na comunidade educadora a identidade de contenção e reafirmar que cada sujeito nesse espaço atua como um educador em todas as suas ações. Como parte da instituição, cada funcionário deve diuturnamente rever e aprimorar seus conceitos, transmitindo confiança aos adolescentes a partir do desempenho de seu trabalho.

Os agentes socieducadores que atuam como referência em sala de aula, quando foram convidados para integrar a equipe pedagógica, relataram que se sentiram desafiados e angustiados com a expectativa da prática multidisciplinar. O resultado desse trabalho coletivo dependia diretamente da construção de uma linguagem comum, onde as questões técnicas e pedagógicas fossem trabalhadas com simplicidade, sem perder o foco no cognitivo, porém permitindo uma flexibilidade para abarcar 
experiências de pessoas com formações diversas e a experiência dos adolescentes/alunos como fator motivador e direcionador para a definição de conteúdos escolares específicos. Norteados por esse prisma, deram início no dia 02/02/09 a essa forma de lecionar, aprendendo e construindo junto com os adolescentes um novo modelo, diferente do modelo tradicional que não atendeu às demandas desse público e, portanto, contribuiu sobremaneira para sua evasão escolar. A grande dúvida e angústia dos agentes era se conseguiriam manter os adolescentes dentro da sala de aula por três horas, apesar do planejamento, visto que inicialmente não contávamos com uma professora, e os agentes, além de fazer a segurança da escola, deveriam fazer também a regência das aulas.

No primeiro momento da aula inaugural, foi construído de forma democrática entre os agentes e os adolescentes os combinados que deveriam funcionar como regra básica da disciplina dentro do espaço escolar. O planejamento escolar foi seguido, logicamente com pequenas adaptações, e realizado semanalmente, com implementações de temas transversais. Para surpresa dos agentes, desde o primeiro dia letivo, os adolescentes sempre faziam os seguintes comentários ao final das aulas: - Já terminou a aula?! O tempo passou tão rápido! E assim, nas primeiras semanas, os agentes fizeram o trabalho de segurança e regência. Um dia chegou uma professora, se apresentou, disse que iniciaria no dia seguinte, mas para surpresa geral voltou somente para se despedir, pois havia sido designada para outra unidade. Finalmente, chegou a atual professora, Marília, que se encaixou como uma luva ao grupo que já havia dado forma à escola.

As limitações impostas pelo tempo de efetivo trabalho desenvolvido com cada adolescente, o perfil do autor de ato infracional que enxerga o sistema socioeducativo como acusador, somado ao histórico pessoal do acautelado, que não construiu sentido em sua relação com a escola regular, orientaram o trabalho escolar na Unidade a partir de temas transversais, como forma de suavizar a exposição dos conteúdos. Podemos exemplificar nossa prática com ações atravessadas pela pedagogia da responsabilidade, fundamentada na ética, aqui entendida como responsabilidade por outrem, como não indiferença ao valor da possibilidade humana de dar prioridade ao outro. O posicionamento dos agentes em sala de aula é um fator relevante para o sucesso da proposta, visto que eles não atuam limitadamente na segurança e na contenção dos adolescentes no ambiente, mas interagem com a regente da turma, formando uma equipe pedagógica valorosa.

Sendo o dia 22 de março o Dia Internacional da Água Doce, trabalhamos por duas semanas esse tema, com o objetivo de conscientizar os adolescentes sobre a importância da água para 
a vida. A partir do tema, foi possível trabalhar conteúdos de matemática, como porcentagens, conteúdos de língua portuguesa nas produções de textos, conteúdos de ciências quanto à formação dos corpos. Outros temas transversais como saúde, higiene, ética e cidadania também foram abordados.

Foi proposta aos alunos a produção de painéis, para exposição na Unidade, tratando do tema água. Os materiais disponibilizados para a produção incluíam revistas com fotos de lugares diversos, fato que os motivou a questionamentos sobre a existência daqueles lugares e a demonstrarem desejo de conhecê-los. Quando explicada a situação da água potável no mundo e a quantidade de água própria para o consumo disponível no Brasil, os adolescentes se posicionaram sobre a posibilidade de ocorrer, no futuro, uma guerra por causa do domínio e da posse das reservas de água potável. Nesse momento, foi possível discutir a diplomacia e a política, sem imposição do tema, o que conduziu a uma participação efetiva dos adolescentes nas discussões.

A leitura da nossa realidade social foi direcionada a partir da abertura de espaço para tratar das alternativas para suprir a falta de água em certas regiões. A nova profissão das cisterneiras do nordeste, o porquê de as mulheres se adaptarem melhor a esse ofício, a diferença entre as cisternas de fornecimento e as de armazenamento de água foram trabalhados com foco no fortalecimento da cidadania e o coletivismo. A ampliação dos horizontes culturais e geográficos despertou o interesse dos alunos para conhecer outras realidades. A contribuição de um agente socieducador com a produção de uma música relacionada ao tema motivou a equipe e os adolescentes a proporem novas produções.

Foi possível aos educadores, no desenvolvimento das atividades, perceber a necessidade de abordar questões de geografia com os alunos, visto que eles demonstraram dificuldade em leitura de mapas e no reconhecimento de sua identidade de cidadão pertencente a um país, um estado e uma cidade. Sua noção de nacionalidade e naturalidade estava aquém do desejado, fato que motivou o convite a um agente socioeducador que não compõe diretamente a equipe, mas que é professor de geografia, a reger uma aula com o fim de suprir as dificuldades detectadas, cuja participação agradecemos. Assim, encerramos o projeto sobre o tema "água", com a perspectiva de trabalhar o tema "identidade nacional". 